\title{
Gender Biases and Discrimination while Hiring
}

\author{
Nida Hassan
}

\section{Abstract}

In the employment market, hiring processes in the organisations are often considered to perpetuate gender equality. The discrimination prevails through implicit and in-group biases. During hiring decisions, marked gender differences in the hiring standards continue to exist for women and men. Counter balancing attempts, such as demonstrating agentic behaviour seem to have been unfavourable in receiving appreciations. Factors like 'accumulation of advantage', ' physical attractiveness' and so forth adds to the 'threat' for the woman candidate. The article proposes that sustained and concrete processes need to be ensured that would defuse gender stereotyping, the latter being an outcome of the human tendency to carve the world into in-group and out-group. Two methods to neutralise gender biases while hiring are recommended in the concluding section.

Keywords: Gender Bias, Hiring Policy, Gender Stereotyping, Employment Market

\section{Introduction}

Multinational companies have found 'strategic' reasons to engage in biased decision making while hiring women. Organisations have been found to increase the percentage of female employees as their strategy to promote their brands as inclusive and create good and

* Management Associate, 20:20 MSL, Bengaluru, India; nida25hassan@gmail.com 
positive publicity. This shift has to be contextualised in the relatively recent cultural shift towards embracing a gender equal and system and a progressive society. An article by Karsten Strauss (2016) entitled "Which Big Tech Companies Employ the Most Women?" provided a comprehensive list of companies that were viewed as most "female-friendly". It clearly showed that hiring and retaining a high percentage of female employees posits a positive public perception of the respective organisations and the hiring process is often a marketing strategy rather than assertive of the core ideations of the company.

Gender biases and discriminations are found to deform hiring decisions and stand as a barrier in terms of employment opportunities for the discriminated group (Petersen \& Togstad, 2004). Continuous research over the years across the fields of management, economics, sociology, and psychology has intended to determine the causes of gender bias. Interventions that can attenuate the effects of gender bias and thus improve hiring practices have been suggested (e.g., Rosen \& Jerdee, 1974; Terborg \& Ilgen, 1975). Biases and discriminations emerge from gender stereotypes. Attempts have been made to motivate employers to gain a conceptual understanding of hiring bias, adopt wellstructured hiring methods and invest in training sessions for hirers.

The process of hiring serves the purpose of selecting an applicant who demonstrates the potential as a proficient worker who can complete the assigned tasks of his/her respective job efficiently and objectively. It has also been argued that hiring practices do not reveal any inherent gender bias. For instance, if female and male candidates with comparable competencies have applied for the same position, it would still be unethical to choose the female candidate over the male candidate (or vice versa) solely on the basis of gender, the reason being that theoretically, gender should not seem to impact the performance of an employee (Alford, 2016).

\section{Common Gender Biases}

The most common gender bias while hiring are implicit bias and in-group bias. Implicit bias has a negative impact as we engage in an unconscious association of traits and behaviours with 
individuals belonging to a particular demographic group (Greenwald, et al., 1998; Nosek, et al., 2005). It has been found to have impaired decision making, not only during the process of hiring but post selection too. We unconsciously allow such associations to influence our perceptions and evaluations. We tend to confirm the stereotypes by being on the lookout for information which is consistent with the stereotypes (Koomen \& Dijker, 1997), thus ignoring the readily available contradicting information (Erber \& Fiske, 1984). For example, if a woman applies for a C-suite position, she might be rejected on the grounds of inability to commit to a long-term career.

Another form of bias is the in-group bias. It refers to the tendency of a person to give preference to their own kind as a way of sustaining a positive social identity. In-group bias can occur consciously or unconsciously. Interestingly, it has been found to occur in well-structured groups as well as randomly assigned groups. This bias can be found in a group formed by a random coin toss as well as a sports team. In-group bias works as we build our self-esteem through belongingness. The presence of someone from an in-group reminds us of that belongingness. While making hiring decisions, the basis for selecting candidates is majorly categorisation driven and not competency driven (Brewer, 1979). We gravitate towards people who are similar to us - the similarities and overlap could include gender, preferences, and regionalist biases. Often decisions are clouded by such in built preferences.

\section{Decision-making Process}

The process of decision-making is a complex one. The decision maker would have to choose from several options that differ from one another in several dimensions. That there are several stages of selecting a candidate based on credentials and step-by-step rejections of other candidates who are not deemed fit was stated by the theory of adaptive decision making (Payne, Bettman, \& Johnson, 1993). In the simplest case, a decision making can take place in two stages: first is the formation of a consideration set, and second is choosing from that very set. This process can be studied in detail and captured in a controlled laboratory task that would require the participant to go through several discrete steps before 
the final choice has been made. In the case of hiring, these laboratory stages correspond to forming a short list before the final choice is made.

The existence of gender biases in decisions of hiring serve as a transgression of the principle of gender equity and forms the basis for sexual discrimination lawsuits. Studies over the decades have supported the possibilities of different standards being applied to men and women. Studies have also shown that men are respected more than women (Biernat \& Kobrynowics, 1997; Foschi, 2000). Men are routinely preferred over women for jobs of high responsibility have been supported by research (Eagly, Makhijani, \& Klonsky, 1992). Same-sex bias was also found to be common. Male raters were found to give higher appraisals of men's performance on the job than their counterparts (Bowen, Swim, \& Jacobs, 2000). A successful woman holding a male-dominated position experiences amplified discrimination and resistance. This has resulted in negative consequences for reward allocation and appraisal. It is due to these biases that women are more likely to reach a plateau rather than higher levels within the organisational hierarchy.

\section{The Barriers and the Counterbalancing Attempts}

A considerable amount of research has been conducted to illustrate how perceived gender differences in assertiveness, intelligence, and ambition prevent women from moving up the ladder. The first barrier they face is during the process of hiring (Glick, Wilk, \& Perreault, 1995). The more obvious solution to this problem is for women to behave more masculine in order to break the gender stereotype (Wiley \& Eskilson, 1985). In identical circumstances, men and women were found to be perceived in different lights. While the man can be viewed as confident and assertive, a woman with a similar approach is most likely to be viewed as conceited and bossy (Trinh, 2015). Unfortunately, such a 'strategy' has not worked in favour of these 'agentic' women. Agentic employees are found to be assertive, independent, competitive, courageous and masterful in achieving the task at hand. If women expressed agent behaviour (to be perceived as qualified for a leadership position), their competence ratings were equal to those of agentic men. But 
they suffered from the backlash effect in terms of social repercussions.

During the hiring process, agentic women might be viewed as competent but insufficiently feminine which in turn impacts their selection. They are also viewed as less socially skilled compared to agentic men, which result in discrimination for "feminized" and not "masculinized" positions. Communal prescription serves as a challenge to the societal developments that threaten the patriarchal society. With more and more movement of women into the paid workforce, they have begun to view themselves as agentic and create such perception for those around.

In the last decade, the onward development of gender wage ratios has been found to slow down. As per the observation of Reskin and Bielby (2005), this is due to the "glass walls" or "glass ceilings effect" that women continue to struggle for esteemed positions along with well-paid occupations.

Rewinding to the hiring stage, a difference in opportunities to correct blunders serve as another major concern for gender bias. Women, who are rejected, immediately look for another job, not giving the employer another opportunity for reconsideration. Even if the women suspect discrimination, they venture into new employment opportunities rather than disputing the discriminated decision, often due to the lack of adequate proof.

\section{Accumulation of Advantage}

The general assumption or schema, in both women and men is that women are absent in higher order positions. This leads to a mechanism called 'accumulation of advantage' where these schemas give rise to behaviours, perceptions, and gauging of performance that accumulate in favour of men and work as a disadvantage for the women (Steinpreis, Anders, \& Ritzke, 1999).

The consequence of such schemas may result in "stereotype threat". It is referred to as a person's psychological experience, wherein the person while engaged in a task will not perform well, because of being aware of the stereotype attached to the person's identity. Thus every potential candidate would walk through the 
doors of a company contemplating whether the stereotypes associated with his/her identity would be advocated by the hirer/company or not. For example, a woman could work towards an interview for a position which is considered as typically "masculine". She is aware of the societal stigma that "women cannot do "masculine jobs", which might probably have a disruptive effect on her performance. This ironically would validate the stereotype which she wanted to disprove.

Research has also brought to the forefront striking relationships between physical attractiveness, the gender of the candidate, and level of job (Cann, Siegfried, \& Pearce, 1981). During the hiring process, attractive males were mostly found to be preferred over unattractive males. For females seeking a non-managerial position, attractive females were preferred, but the reverse was found when females applied for managerial roles. In the latter case, physically attractive women were explicitly at a disadvantage.

\section{Women as Employment Decision Maker}

In the past few decades, there has been a slender rise in the number of female managers due to legal pressures to bring diversity in organisations (Bartol \& Wortman Jr, 1975). Thus, there has been a significant rise in employment decisions being made by women as compared to the situation a few years back. It then brings us to the question of how the gender of the decision maker influences the selection of applicants during the process of hiring. Research has shown that sex effects may be a significant concern for organisations with women being more lenient evaluators than their male counterparts and preferring more of women to be on board leading to in-group favouritism (Rose \& Andiappan, 1978). In contrast, equally qualified women were found to be evaluated (by male evaluators) unfavourably in comparison to men, especially for difficult managerial positions.

The pressure to hire women is more likely to arise from women who are comparatively better represented in a company or industry. It can reflect internal department or external administrative commitment to dissolve gender discrimination in the hiring process. Commitment, whether internal or external, 
cannot be spontaneous without the support and efforts of higher management committed to having better representation of women.

\section{Conclusion}

Individuals categorise the world into in-group and out-group members and automatically applies stereotypes to evaluate them. Implementing the measures to alleviate the stereotypes is one of the benchmarks that indicate that the society progresses. As a preliminary attempt to remove gender stereotypes, companies should revisit and restate their job descriptions. Job descriptions generally have the features that may encourage or discourage applicants. A job that is in need of "dominant" or competitive candidates might discourage women from applying for such positions due to stereotyping tendencies, such as certain personality traits being positively associated with men at the workplace and negatively with women. Employing candidates from the same categories or groups may give rise to cultures of workplace not based on transparency. Qualified out-group members may show reluctance in applying for such positions.

Another practice that the company can encourage is a consistent evaluation of all resumes. This can be done by developing a standard evaluation form with a detailed scoring metric. Prior to the interviewing process, the interviewer shall identify and understand the behaviour relevant to the open position. There could be situations where the interviewer will have to select between two applicants who might have similar qualifications but differ on the basis of gender. Clarity in communication regarding the standards expected from the candidate encourages transparent hiring practices. To make sure that the elaborate and expensive process is not corrupted by biases, continuous analysis of the hiring process needs to be done. 


\section{References}

Alford, H. L. (2016). Gender bias in IT hiring practices: An ethical analysis. Student Scholarship-Computer Science, 1-13. Retrieved from http://digitalcommons.olivet.edu/cgi/viewcontent.cgi?article=1000 \&context $=$ csis_stsc

Bartol, K. M., \& Wortman Jr, M. (1975). Male versus female leaders: Effects on perceived leader behavior and satisfaction in a hospital. Personnel Psychology, 28(4), 533-547. doi:10.1111/j.1744-6570.1975.tb01391.x

Biernat, M., \& Kobrynowics, D. (1997). Gender and Race-based standards of competence: lower minimum standards by Higher ability standards for devalued groups. Journal of Personality and Social Psychology, 72(3), 544-557.

Bowen, C.-C., Swim, J. K., \& Jacobs, R. R. (2000). Evaluating gender biases on actual job performance of real people: a meta-analysis. Journal of Applied Social Psychology, 30(10), 2194-2215. doi:10.1111/j.15591816.2000.tb02432.x

Brewer, M. B. (1979). In-group bias in the minimal intergroup situation: a cognitive-motivational analysis. Psychological Bulletin, 86(2), 307-324.

Cann, A., Siegfried, W. D., \& Pearce, L. (1981). Forced attention to specific applicant qualifications: impact on physical attractiveness and sex of applicant biases. Personnel Psychology, 34(1), 65-75. doi:10.1111/ j.17446570.1981.tb02178.x

Eagly, A. H., Makhijani, M. G., \& Klonsky, B. G. (1992). Gender and the evaluation of leaders: a meta-analysis. Psychological Bulletin, 111(1), 322.

Erber, R., \& Fiske, S. T. (1984). Outcome dependency and attention to inconsistent information. Journal of Personality and Social Psychology, 47(4), 709-726.

Foschi, M. (2000). Double Standards for competence: theory and research. Annual Review of Sociology, 26, 21-42. doi:10.1146/ annurev.soc.26.1.21

Glick, P., Wilk, K., \& Perreault, M. (1995). Images of occupation: components of gender and status in occupational stereotypes. Sex Roles, 32(9/10), 565-582.

Greenwald, A. G., McGhee, D. E., \& Schwartz, J. L. (1998). Measuring individual differences in implicit cognition: the implicit association test. Journal of Personality and Social Psychology, 74(6), 1464-1480.

Koomen, W., \& Dijker, A. J. (1997). Ingroup and outgroup stereotypes and selective processing. European Journal of Social Psychology, 27, 589-601. 
Nosek, B. A., Greenwald, A. G., \& Banaji, M. R. (2005). Understanding and using the Implicit Association Test: II. method variables and construct validity. Personality and Social Psychology Bulletin, 31(2), 166-180. doi:10.1177/0146167204271418

Payne, J. W., Bettman, J. R., \& Johnson, E. J. (1993). The adaptive decision maker. New York, NY: Cambridge University Press.

Petersen, T., \& Togstad, T. (2004). Getting the Offer: sex discrimination in hiring. IRLE Working Paper(No. 104-04). Retrieved from http:/ / irle.berkeley.edu/files/2004/Getting-the-Offer.pdf

Reskin, B. F., \& Bielby, D. D. (2005). A sociological perspective on gender and career outcomes. Journal of Economic Perspectives, 19(1), 71-86.

Rose, G. L., \& Andiappan, P. (1978). Sex effects on managerial hiring decisions. Academy of Management Journal, 21(1), 104-112.

Rosen, B., \& Jerdee, T. H. (1974). Influence of sex-role stereotypes on personnel decisions. Journal of Applied Psychology, 59(1), 9-14.

Steinpreis, R. E., Anders, K. A., \& Ritzke, D. (1999). The impact of gender on the review of the curricula vitae of job applicants: a national empirical study. Sex Roles, 41(7/8), 509-528.

Terborg, J. R., \& Ilgen, D. R. (1975). A theoretical approach to sex discrimination in traditionally masculine occupations. Organizational Behaviour and Human Performance, 13, 352-376.

Trinh, S. L. (2015). Enjoy your sexuality, but do it in secret: exploring undergraduate women's reports of friends' sexual communications. Psychology of Women Quarterly, 40(1), 96-107. doi:10.1177/ 0361684315596914

Wiley, M. G., \& Eskilson, A. (1985). Speech style, gender stereotypes, and corporate success: What if women talk more like men? Sex Roles, 12(910), 993-1007. doi:10.1007/BF00288100 